\title{
Research on Reform of College English Teaching Mode in Independent Colleges
}

\author{
Xuemin Heng \\ Xiamen University Tan Kah Kee College, Xiamen, Fujian, China \\ Jasonhxm7708@163.com
}

Keywords: College English, Independent College, Teaching Mode Reform

\begin{abstract}
English teaching in independent colleges has always been a part which shall be paid close attention to in College English teaching. With the deepening reform of teaching nowadays, English reform in independent colleges also becomes a focus of study. Under the background of educational internationalization, this paper summarizes of and reflects on the various problems existing in teaching, and emphasizes on the reform of the original teaching methods of College English in independent colleges, improvement of educational system, continuous promotion of the reform of College English in independent colleges, and cultivation of application-oriented talents with innovative capacities who can adapt to the social development. Based on the current status of College English teaching in independent colleges, this paper probes into the functional orientation of College English teaching in independent colleges in the reform of College English teaching, and thereby puts forward a teaching model of College English that is fit for the current social and economic tendency.
\end{abstract}

\section{Introduction}

Along with the economic globalization and integration of science and technology, we are now facing an international environment with increasingly frequent exchanges and increasingly fierce competitions. English, as a communication tool of international common language, is becoming more and more important during the process of exchanges in this international environment. Graduates mainly rely on literature to understand the social adaptation of the overseas science and technology development. Nowadays, with the increasingly frequent exchanges between China and other countries, the demand for the comprehensive application of English is also ever-growing. In the new regulations promulgated by the Ministry of Education in 2004, the teaching goal of College English was determined as training students' comprehensive application ability of English, especially the listening and speaking ability, so as to enable students to have an effective oral and written information exchange in English in their future work and social intercourse, at the same time, to enhance students' independent learning ability and improve their comprehensive cultural quality to meet the needs of China's economic development and international exchanges. "Change the teaching mode from the pure language knowledge transmission to both language knowledge teaching and cultivation of language culture and professional English so as to continuously enhance students' independent learning ability, thinking ability and comprehensive application ability of language"[1]is a start of the National College English teaching reform. College English teaching is an organic integral part of higher education and the course of College English is a compulsory course for college students, moreover, College English teaching has received unprecedented attention and made many remarkable achievements in colleges and universities of China. With the further deepening of China's reform and opening up, the demand for excellent talents who not only have professional knowledge but also master foreign languages is urgently increasing day by day, which makes College English teaching face new opportunities and challenges. Looking back on the teaching of College English of more than twenty years in China, the current situation of College English teaching is that English is often taught theoretically as a kind of knowledge rather than being learned or cultivated as a practical skill or a kind of cultural quality by combining the language with its cultural background. As a result, an unprecedented large area of test-oriented 
teaching phenomenon occurred, which brought a group of “deaf English" and "dumb English" learners who have high marks but low practical ability. Therefore, students still feel difficult to speak once making communication in English, and the language loses its function as exchange. "There are two shortages in this training mode, of which, the first is the neglect of the essence of language, namely communication, therefore, students who are trained are lack of leaning motivation and language communication competence, not to mention their innovative ability; the other shortage is the neglect of analysis of the foreign language learning needs, that is, it neglects the needs of society and employers for college students' foreign language competence, and the gap between the current level of students and the level they want to achieve.”[2]

\section{Analysis of the current status of College English teaching in Independent Colleges}

Independent Colleges are institutions of higher education run by non-state financial funds and they implement the undergraduate education and adopt new running mode under the new management system. The source of their students is relatively narrow and the cultural foundation of their students is relatively weak. In view of this particularity, the basic education for their students is more important than that in other regular colleges and universities. Some problems exist in the College English teaching in Independent Colleges, such as obsolete teaching objectives, poor foundation of students, low self-learning ability, serious deletion of English classes, instability of teachers. Therefore, under the training mode of application-oriented talents, the reform of College English is imminent. Though the reform of College English teaching has made some periodical achievements in the recent years, many Independent Colleges have not yet formed a unique, scientific and relatively complete College English teaching system that can be used for reference by other Independent Colleges, and are still blindly following the traditional College English teaching mode in their mother schools without reflecting the uniqueness of cultivating high-quality application-oriented talents that the Independent College should have. After entering the network era, the learning APP, search engines, educational video and so on have also had a certain impact on the traditional single blackboard English teaching. Then, how we deal with these changes and challenges? English teachers from Independent Colleges have to reform their teaching ideas and teaching methods.

In College English teaching, students should be trained to have good comprehensive English application ability and self-help and self-learning ability, so that they can effectively learn and use English in their future study and work, including oral communication ability, written expression ability, academic exchange ability and research ability, etc. Meanwhile, the humanistic characteristics of English study should be focused on so as to cultivate students' comprehensive cultural quality and meet the needs of China's social development and international exchanges. "English is a professional tool for students. If there is no professional English teaching, it will be difficult for students to apply English to their future career, which will lead to the decline of English learning enthusiasm."[3]Compared with the key universities and normal universities which focus on academic researches, Independent Colleges have trained a lot of practical talents for the society; but at the same time, some problems have been exposed in management and teaching because of the restrictions on the entrance examination scores of the students enrolled by Independent Colleges, the relatively weak foundation of cultural courses of students, or the serious situation of subject preferences. As a result, it is hard for teachers in Independent Colleges to arrange their teaching activities or arrange the College English teaching well.

Nowadays, all colleges and universities over China are facing a comprehensive transformation and reform, and the problems faced by College English teaching in the past are getting particularly prominent, for example, students have the weak foundation of English and poor comprehensive language application, and lack of independent self-learning habits, while College English teachers have single knowledge structure and the obsolete teaching methods. Under this situation, the current College English teaching mode is hard to serve the objective of training the compound application-oriented talents. After entering the Internet + era, the new teaching mode, such as MOOCs, micro class and network study, has brought new challenges to the traditional and single 
College English teaching method. How to find a new teaching mode which can not only retain the original teaching advantages, but also connect with the new background so as to better play the role of College English teaching in personnel training has become the focus of transformation work of many schools. Language is the most important communication tool for human beings and also the carrier of national culture. In College English teaching, the education circle in China agree that foreign language teaching in colleges and universities should cultivate students' ability to understand different cultures. Only in this way can students' comprehensive language application ability be gradually improved to meet the needs of the rapid development of our society.

The number of College English teachers in Independent Colleges is small, but the number of students in the classes is large, so the teaching tasks are heavy (usually one teacher has more than 16 classes per week). Therefore, teachers do not have much time and energy to study the relevant theories deeply in their daily teaching. Moreover, their knowledge structure is single and their understanding of the purpose of English teaching is unclear, and they do not care about the hot topics of educational theory and practice, which not only hinders the improvement of teachers' own quality, but also fundamentally affects the improvement of College English teaching quality in Independent Colleges. On the whole, there are many problems existing in the setting of English curriculum of Independent Colleges, such as the unclear orientation of curriculum objectives, monotonous and inactive teaching contents, unreasonable curriculum structure and the extremely lack of high-quality teaching materials suitable for Independent Colleges. Teaching in large class can also affect the effect of classroom teaching, which is difficult to ensure the quality of teaching because it takes a lot of time to maintain classroom order and teachers have no time to take care of all students, but can only take into account the majority. On this point, large-class teaching is neither helpful to mobilize and play the enthusiasm of students to study independently, nor conducive to students' cultivation of English comprehensive practical ability training. "Teachers' responsibility is to create conditions to help learners give full play to their independence and creativity; educators should not only care the effectiveness of students' learning, but also pay attention to the improvement of students' personality and the realization of students' values.”[4]

Based on the questionnaires conducted by the students in our college, most of students learn English not only for passing tests but also hope to apply English into practices so that they can communicate proficiently in oral English and improve their practical abilities. However, the present teacher-centered, chalk-book-class teaching model is not only far from students' expectation but also not up to the requirement of the new curriculum. At present, teachers mostly adopt the traditional classroom teaching mode, in which, teachers are still the center of teaching who are responsible for speaking while students keep notes. In this “cramming” teaching mode, students can not improve their basic knowledge of English greatly, and their practical ability of English is still low. Some teachers believe that as long as we use multimedia, the quality of teaching will be improved, so they often prepare colorful multimedia to attract students' attention, but some students only pay attention to the gorgeous music and moving pictures when listening, but put knowledge in a secondary position. Although most colleges and universities have made great progress in hardware facilities, these hardware facilities are lagging behind or are not improved with the times in some colleges and universities. Therefore, the huge role of these hardware teaching resources is difficult to play, and most of the educational resources are idle and wasted. Furthermore, teaching activities are too formal. With the wide application of computer technology in the University and my teaching process, teachers are more and more dependent on computer equipment in the classroom. Therefore, in College English teaching, teachers should embody the teaching concept of "student orientation" and "teaching students in accordance with their aptitude".

\section{Selection of strategies in reform of College English teaching}

Higher education in the new era and under the new background determines the new development of College English teaching, that is, we shall change the traditional teaching concepts and actively create new models. Taking students as the main body is the fundamental principle to carry out all teaching activities. In College English teaching, effective methods should be adopted to integrate 
the ability of listening, speaking, reading, writing and translation into every teaching link, and the teaching contents should cover language application skills, humanistic quality, cross-cultural communication, professional knowledge and so on, for providing students with a practical and diversified curriculum system. Innovate the teaching mode of College English, and combine the network with classroom teaching: with the development of modern information technology, the connotation of teaching has undergone a qualitative change, for which, the teaching content, teaching time and space are no longer confined. Then, how to combine abundant network teaching resources with classroom teaching to cultivate students' independent learning habits and critical thinking is the key to the innovation of College English teaching mode. Gradually establish a scientific and perfect evaluation system of the whole process: we shall establish a whole process assessment mechanism from pre-class online learning records to teacher-student interaction effect in classroom and to after-class practical operation results, to cover students' listening, speaking, reading and writing skills on online, in classroom and after-class. The reform of teaching mode will inevitably lead to changes in management, so schools should manage the College English teaching with a more flexible credit management system. In the construction of teaching staff, the first step is to set up a professional teaching team and introduce teachers of different professional courses so that they can learn from each other and draw on the strong points of others to make up for their own weak points.

At present, a large number of College English teachers in China mainly adopt the fundamental English teaching and most of them have learning background of English and American Literature and Linguistics. Therefore, in order to better realize the importance of academic English teaching in the whole English teaching and to promote the quality of professional English teaching as much as possible, teachers must change the contents of English teaching on the basis of being familiar with the contents of general English teaching. Only by changing the subject knowledge can teachers better implement this teaching task. First of all, teachers should renew their teaching concepts, not only imparting knowledge to students, but also paying attention to students' development. Moreover, teachers should impose such a concept on students that English learning is not to cope with examinations or obtain certificates, but to cultivate their own language ability so as to develop themselves in many ways, improve their own quality, and regard English learning as a quality education. Only by setting up correct educational ideas can we implement the correct educational methods. Secondly, teachers should make full use of the modern educational technology in teaching.

"Classroom teaching is the main position for schools to achieve teaching objectives, the basic form of school education and teaching activities, a scientific and reasonable curriculum, and the main channel for Independent Colleges to deepen the reform of College English teaching and to implement the "National Medium and Long-term Education Reform and Development Policy (2010-2020)" [5]. Classroom teaching has no fixed mode. We cannot say which teaching mode is the best. As long as the teaching mode meets the actual needs and achieves the purpose of language learning and communication, we can have a try. Teachers should participate in students' learning not only as educators, but also as organizers, managers, inspirers and even collaborators, so that they can maintain a harmonious and cooperative relationship with students in the classroom, make students can not only feel pressure, but also be full of vitality in learning. It is necessary to strengthen the role of College English Teaching and Research Office and to arrange experienced professors to give demonstration lessons to young teachers or to listen to classes of young teachers regularly by means of the "senior staff guide new staff and one helps one" during the regular activities of Teaching Research Offices, in order to enhance young teachers' quality and teaching ability, promote their rapid growth and cultivate their own team.

Besides, the training of English teachers and the exchange of teaching experience should be strengthened. For example, a tutorial system can be implemented for teachers who have just been engaged in English teaching, that is, teachers with rich teaching experience and high comprehensive qualities should act as tutors for these new teachers to guide their teaching and educating. In addition, teachers should be encouraged to take part in teaching skill matches regularly to exchange 
teaching experiences. College English teachers should strengthen their awareness and ability of lifelong learning, consciously become learning-oriented teachers so as to achieve the goal of "never too old to learn" and realize "mutual development of teaching and learning" for constantly improving teaching concepts and innovating teaching methods. At the same time, Independent Colleges should take positive measures to improve the treatment of teachers, optimize and stabilize the teaching staff to prevent them from being easily lost. In view of the great fluidity of College English teachers and the different levels of teachers in Independent Colleges, the college management level should also change minds, fully realize the auxiliary role of College English as a basic course, strengthen investment, improve teachers' treatment and enhance their status. At the same time, College English teachers should constantly strengthen their moral cultivation, update their knowledge reserves in time, and improve their teaching and scientific research ability. In terms of construction of the teaching staff, due to the special business operation mode of the Independent Colleges, there are few opportunities for teachers to get in-service training or to study abroad. Moreover, teachers have heavy teaching tasks, and most of them have no time or energy for teaching research and self-learning improvement. Because of the above disadvantages, the mobility of teachers in Independent Colleges is relatively large.

In terms of curriculum design, College English graded teaching is an attempt in the reform of College English teaching, also an important part of the teaching reform in Independent Colleges. The graded teaching system has changed the traditional class-division mode of "non-discretionary implementation" in the former College English teaching, and avoided the situation that knowledge is too easy for excellent students and too hard for poor students. Higher learning goals and more challenging learning tasks can be arranged for the excellent students, so as to enhance students' interest in English learning, which is conducive to the personality development of students. Some of the freshmen with high English proficiency can be selected to take part in English improvement classes to strengthen their comprehensive application ability and communicative skills, while others can be taught in parallel classes to lay a solid foundation and improve their listening and speaking skills. According to the students' English proficiency, the students in Independent Colleges are classified to accept the different teaching objectives, teaching contents, teaching plans and teaching evaluations. Teaching students in accordance with their aptitude and grading them will help Independent Colleges to formulate teaching plans and organize teaching activities more comprehensively, scientifically and systematically, to cultivate students' comprehensive ability to use English more effectively, and to improve their own teaching quality. The practice of graded teaching fully embodies the people-oriented teaching concept, realizes the actual needs of individualized teaching, and makes College English teaching out of the traditional, time-consuming and inefficient teaching mode. Teaching design and teaching methods are important points in implementing teaching. In the process of designing College English curriculum, the first step is to do demand analysis, that is, to clarify the purpose and requirement of students' English learning and make students study in accordance with the general requirement of College English in the first semester. The students who pass the CET-4 at the end of the first semester can get study with higher requirements in the second semester and take the CET-6 at the end of the semester. In the future, the College English should focus on academic English and extended courses, emphasis on strengthening students' reading, writing and oral expression ability in academic English and promote students' awareness of cross-cultural communication.

Based on the school-running orientation, the role of College English should be firstly clarified and importance should be attached to students' humanistic quality and intercultural communication ability so as to meet the needs of social development and industry in China. With the favorable support of modern science and technology, the time and space conditions of College English teaching should be met to make sure that students can develop towards the direction of personality and independent learning. The excellent part of modern information technology and traditional teaching mode should be combined to give full play to both advantages. Classroom teaching is an effective assessment and expansion of online learning. In the process of reform of College English teaching, it is very important to change the situation that College English teachers have a single 
professional knowledge, which is an effective way to improve the teaching of College English teachers while enriching and updating the knowledge that students have learned. At the same time, we should give full play to the advantages of all kinds of teachers to improve teaching efficiency and quality by team operation, and promote teaching reform by cooperative research. With the development of network technology, we are in an era of "information explosion". It is no longer difficult to obtain information, but it is hard to find and analyze the information we need. According to statistics, English plays a vital role in the language used on the Internet. How to use English for learning and professional search has become a necessary skill for students. College English teachers can assign students some homework for independent learning to help them use the Internet effectively. The convenient hyperlinks in multimedia courseware makes teachers save a lot of time in writing on blackboard and workload in class, then teachers can supplement and broaden the teaching contents to further strengthen the explanation of key points, difficulties and new progress of the course, so as to improve the information quantity and quality of teaching. During the process of English teaching, because of different levels and different abilities to accept and understand knowledge of students, it is hard for teachers to carry out targeted learning guidance when facing dozens of students at the same time under the premise of limited teaching time, as a result, the purpose of teaching students in accordance with situations and individualized study is difficult to achieve. Internet has opened up a new way for teaching reform. With the help of network teaching system, teachers can provide students with enough abundant learning resources and access means in the classroom, so that they can do their best to get what they demand and know what they need. At the same time, teachers can also incorporate text and language materials into the self-made English teaching web pages for students to choose freely and teach students in accordance with their aptitude, which is convenient for learners to learn and understand the latest knowledge of current social development and scientific and technological progress, and can also get the "personalized" teaching guidance from teachers. On the internet, the teaching contents, textbooks, teaching methods and auxiliary teaching methods can vary based on different students and different demands, which have strong flexibility, from which, students' initiative and personality potential can be fully utilized to realize their personalized learning.

During teaching, teachers should change their roles from the original knowledge disseminator to the manager, organizer, motivator, facilitator, diagnoser and instructor. Teachers should give students plenty of space to make them participate actively in the situation and communicate with each other with language. At the same time, teachers shall intentionally cultivate the students' six kinds of intelligent abilities in the aspects of acceptance of language information, delivery of language information, observance, memory and association, logical thinking and innovation, as well as the independent learning, and pay attention to their guidance roles in homework evaluation and test paper analysis. At the time of reform of College English teaching in various schools, "micro-course", MOOCs and "flip-classroom" have been frequently recognized by teachers and students, which have injected new vitality into College English teaching. In view of the characteristics of the course of College English in Independent Colleges, relevant "MOOC" development plans can be formulated, under which, we can not only share high quality courses on the Internet platform, but also focus on the globalization, localization and implementation of "flip-classroom" and so on. Multimedia resources are database of a large number of resources for teachers, by which, teachers can share resources on this platform, jointly explore and improve their teaching methods. Moreover, teachers should attach importance to the communication with students in teaching. "In classroom teaching, learners are the center, and teachers should help language learners to develop their own potential so as to develop their individual interests and emotions." [6] Classroom teaching needs interaction, therefore, teachers shall have body language besides eye contact in class, since rich body language is conducive to attracting the attention of students, and thus more helpful to inspire the interaction between students and students, students and teachers. It is one of crucial points to firstly improve teachers' teaching quality in order to improve the quality education of students. 


\section{Conclusion}

A College English teacher in an Independent College shall not stop his own English learning after acquiring a certain degree, but shall constantly improve his English teaching level and expand teaching knowledge with the change of educational situation. In the reform of College English teaching, the course content and teaching mode determine students' interest in learning, so students can make progress only under the guidance of interest. On this basis, in teaching practice, teachers, on the one hand, should understand students' needs, learning concepts, motivations, and difficulties and learning methods in order to constantly adjust their teaching; and on the other hand, teachers should be good at adopting some correct and effective methods to create a good language learning environment, create a relaxed and pleasant classroom atmosphere, help students correctly understand and deal with the relationship between taking examination for acquiring certificate and training practical application ability, inspire students' enthusiasm for learning, and improve the quality of classroom teaching. Only by combining the needs of students, teaching content, teaching form and teaching management can we truly achieve "classified guidance, teaching according to students' aptitude" and realize "scientific, systematic and personalized English teaching” in the reform. Hence, teachers should combine their individualized teaching with the classes under the new model and new ideas, constantly make exploration in the practice of College English teaching, dare to make innovations, accumulate teaching experience, and strive to acquire the best teaching results, so as to make joint contributions to the reform of College English teaching.

\section{References}

[1] Ni Yang. Study on Teaching Reform of College English in Applicable Independent College under "Belt and Road Initiative” [J]. Language Arts and Sports Research, 2017(12) 373.

[2] Dingfang Shu. Problems and Countermeasures in Reform of Foreign Language Teaching [M]. Shanghai: Shanghai Foreign Language Education Press, 2004. 20.

[3] Yu Liu. Study on Reform of College English Teaching Mode in Independent Colleges [J]. Journal of Lanzhou Institute of Education, 2015 31(6) 138.

[4] Yumei Zhu. Exploration on Reform of College English Teaching Mode-Case Study on Reform and Practice of English Course in Independent Colleges [J]. Foreign Languages and Their Teaching, 2006(6) 37-40.

[5] Hongxia Fu. Research on College English Teaching Reform in Independent Colleges [J]. Education Teaching Forum, 2018(7) 114.

[6] Wei Zheng. Exploration on Reform and Practice of English Teaching in Independent Colleges

[J]. Teaching of Forestry Region, 2016(10) 22. 